\title{
USE OF UNMANNED AERIAL VEHICLES ON EXAMPLE OF PHANTOM 4 (STANDARD) FOR CREATING DIGITAL TERRAIN MODELS
}

\author{
Mikhail Aleshin $^{1}$, Larisa Gavrilova ${ }^{2}$, Andrey Melnikov ${ }^{1}$
}

${ }^{1}$ Peoples' Friendship University of Russia, Russia; ${ }^{2}$ State University of Land Use Planning, Russia m.aleshin.net@mail.ru, wernjer@gmail.com, acornum@mail.ru

\begin{abstract}
Nowadays, more and more unmanned aerial vehicles (UAVs) are used to solve various problems. The use of specialized unmanned aerial vehicles causes some difficulties. The UAVs are quite expensive, and you need to have the necessary qualifications in order to effectively operate them. At the same time, there are a lot of non-specialized UAV models, which are much cheaper and easier to use. But the question remains about their capabilities. For example, how to generate a digital terrain model (DTM) of the required quality in order to use it in land use planning? The report is tasked with the scientific (theoretical) substantiation of the need for preliminary calculation of the parameters of aerial survey from the UAV to ensure a required accuracy of the DTM. The calculation involves taking into account the pixel size of the sensor, overlap, image base and the required RMSE of the heights. The report presents a comparison of two methods for DTM generation. Namely, the DTM generation as a result of photogrammetric processing of images obtained during aerial surveying with UAVs and a more traditional method of ground surveying using a modern total station. Obviously, the main criterion for the quality of the generated DTM is the accuracy of the spatial coordinates of its points. This paper presents the qualitative comparison of DTM that were generated using different engineering equipment and using various processing methods. The analysis of the results is based on the least squares method. The study concluded that the use of the photos from the UAVs is effective for the DTM generation.
\end{abstract}

Keywords: digital terrain model (DTM), unmanned aerial vehicle (UAV), aerial surveying, topographic surveying, RMSE (root mean square error).

\section{Introduction}

The object of the study: an open area in the landscape reserve Teply Stan was chosen for the experiment. The area of $2150 \mathrm{~m}^{2}$ is a small slope with a vertical distance of $9 \mathrm{~m}$ and is shown in Fig. 1 .

Considering that the area of the object is relatively small, and there are no objects interfering with the line of sight, it was decided to use the ends of the baseline 1000-2000 as control points (Fig. 1).

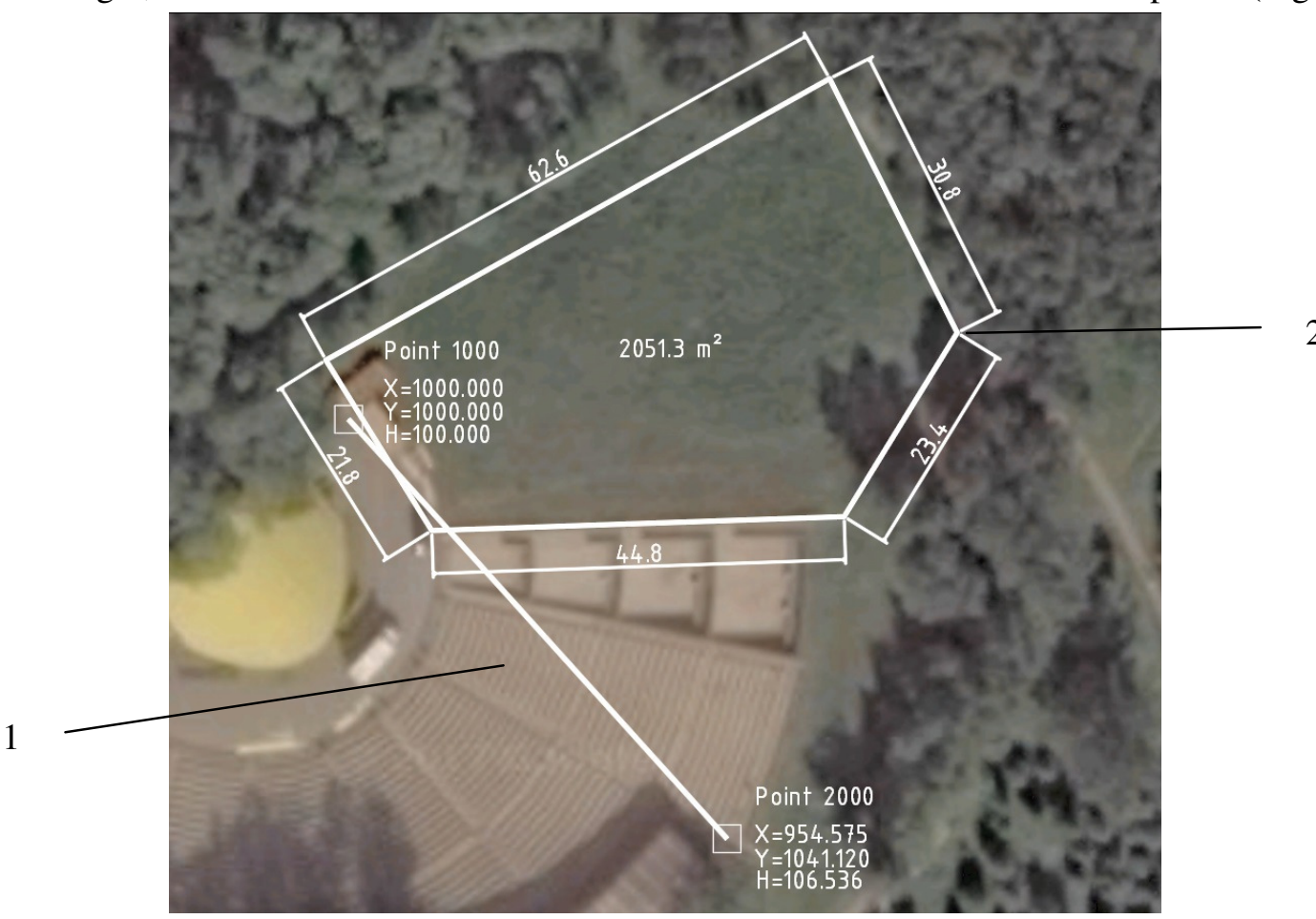

Fig. 1. Scheme plot: 1 - baseline; 2 - border area

The basis measurements were made with a Leica TS 09 Plus total station, the characteristics of which are presented in Table 1. 
Technical characteristics of the total station

Table 1

\begin{tabular}{|c|l|}
\hline Measuring method & \multicolumn{1}{|c|}{ Accuracy } \\
\hline Angular accuracy & \multicolumn{1}{|c|}{ 3" (1 mgon $)$} \\
\hline \multirow{3}{*}{ Distance measurement with reflector } & Precise + : $1.5 \mathrm{~mm}+2.0 \mathrm{ppm}$ \\
& $\begin{array}{l}\text { Precise Fast: } 2.0 \mathrm{~mm}+2.0 \mathrm{ppm} \\
\text { Tracking: } 3.0 \mathrm{~mm}+2.0 \mathrm{ppm}\end{array}$ \\
\hline
\end{tabular}

Measurements of the length of the basis and the vertical distance between its ends were carried out in the forward and reverse direction with the subsequent equalization based on the least squares method in the software Credo DAT 4.0. The coordinates of the ends of the basis were specified in the assumed coordinate system, while the grid azimuth of the line 1000-2000 was taken as the magnetic azimuth of this direction.

\section{Materials and methods}

It was decided to assess the accuracy of the generated DTM in two ways.

In the first method the accuracy was estimated using the differences in the coordinates of points of two independent models generated by the photogrammetric method from images taken from a UAV $[1 ; 2]$.

In the second method the accuracy was estimated by the differences in the coordinates of the points of the two models, one of which was generated by the photogrammetric method, and the second by the geodesic method.

Before aerial surveying, artificial targeting wascarried out.

Target is a black cross, printed on a white sheet of A4 paper. Later, the ground targets were used as reference and control points. The thickness of the shoulders of the crosses of the targets was calculated based on the resolution on the ground with the determined image geometry. A total of 40 points were marked. The flying height was pre-calculated based on the unspecified characteristics of the camera and in order to guarantee DTM accuracy [3;4].

The solution of such tasks of land use planning as

- development of projects for the anti-erosion organization of the territory;

- designing rice checks;

- reclamation of disturbed lands;

- terracing of slopes;

- determination of the boundaries of the water edge in the design of hydraulic structures;

- counting the volume of earthworks

requires the use of topographic plans with a height of the relief section not exceeding $0.5 \mathrm{~m}$. Thus, the accuracy of the DTM should be no rougher than $0.12 \mathrm{~m}$.

Based on these considerations, the flying height was pre-calculated by the formula 1 in order to guarantee DTM accuracy of $0.10 \mathrm{~m}$ [5-13].

$$
H=\frac{m_{h} \times b}{m_{x: y}}
$$

where $m_{h}-$ RMSE of the of the heights, $\mathrm{m}(0.10 \mathrm{~m})$;

$b$ - image base, pix (800 pix);

$m_{x: y}-$ RMSE of image measurement, pix (3 pix).

So, the flying height was $26 \mathrm{~m}$, aerial photo scale was 1: 7200 .

A large overlap (80\%) is chosen to reduce the effect of distortion, since in this way the central parts of the images will be included in the processing. The direction of the flight strip is aligned with the long side of the image, which is 4000 pixels long [4;14].

The coordinates of the centers of the ground targets were obtained as a result of the total station survey and processing of the results in the software Credo DAT 4.0. The error in determining the 
coordinates of the ground targets is $0.004 \mathrm{~m}$ and is calculated by the formula 2. In this case, under the ordinary conditions, the error of the coordinates of the DTM points, generated using the total station survey, is $0.05-0.10 \mathrm{~m}$.

$$
m_{P}^{2}=m_{A}^{2}+\left(\frac{m_{\beta}}{\rho}\right)^{2} S^{2}+m_{S}^{2}
$$

where $m_{p}$ - RMSE of the coordinates of the ground targets, $\mathrm{m}$;

$m_{A}-$ RMSE of the coordinates of the ends of the basis, $m$;

$S$ - distance from the ground target to the end of the basis, $\mathrm{m}$;

$\rho$ - quality of arc-seconds in the radian;

$m_{\beta}-$ angular accuracy of the total station, sec;

$m_{S}-$ distance measurement precision of the total station, $\mathrm{m}$.

After the total station survey was performed, aerial surveying of the object was performed using a Phantom 4 (standard) UAV, the characteristics of which are listed in Table 2.

Table 2

Technical characteristics of UAV

\begin{tabular}{|c|c|}
\hline Position & Description \\
\hline Sensor & $1 / 2.3^{\prime \prime}$ Effective pixels: $12 \mathrm{M}$ \\
\hline Lens & FOV ( Field Of View ) $94^{\circ} 20 \mathrm{~mm}(35 \mathrm{~mm}$ format equivalent) $\mathrm{f} / 2.8$ \\
focus at $\infty$
\end{tabular}

As a result of aerial surveying, more than two hundred photos were taken, and after rejection forty photos were included in the photogrammetric processing. Image processing was carried out in the software "AgisoftPhotoscan". Before processing, all telemetry data from the photos were deleted [14]. Photogrammetric processing in AgisoftPhotoscan included several steps:

1. import of control point coordinates,

2. measurement of the coordinates of the reference points in each image,

3. selection and measurement of the coordinates of tie points and block adjustment,

4. generation of a dense point cloud of a digital terrain model,

5. orthophoto production,

6. export coordinates of control points in the txt file.

To generate two independent DTMs two processing options were performed, which differed in a set of reference points. The reference points were located at the edges of the contour of the object. The measurement of the coordinates of the reference points on the images occurs in manual mode, all other processing steps are automated. 
As a result, 3 DTMs were created, one - as a result of a total station survey and two independent models were obtained as a result of aerial survey using UAVs.

In the first case, the accuracy was estimated by the differences of double measurements, namely by the differences of coordinates of the points of the two models generated with the help of the photos from the UAV [15-17]. The calculation of the differences of coordinates is presented in Table 3. The RMSE of the plane coordinates was calculated by formula 3, and the RMSE of the height - by formula 4.TheRMSEoftheplanecoordinateswas $0,021 \mathrm{~m}$, and the RMSE of the heights was $0,046 \mathrm{~m}$.

$$
\begin{gathered}
m_{X: Y}=\sqrt{\frac{\left[d X^{2}\right]+\left[d Y^{2}\right]}{2 n}} \\
m_{H}=\sqrt{\frac{\left[d H^{2}\right]}{2 n}}
\end{gathered}
$$

where $m_{x: y}-$ RMSE of the plane coordinates, $\mathrm{m}$;

$d X ; d Y$ - differences of the plane coordinates, $\mathrm{m}$;

$m_{H}-\mathrm{RMSE}$ of the heights, $\mathrm{m}$;

$d H$ - differences of the heights, m;

$n$ - number of the points.

Table 3

\begin{tabular}{|c|c|c|c|c|c|c|c|c|c|}
\hline \multirow{2}{*}{ Point } & \multicolumn{3}{|c|}{ Model 1} & \multicolumn{3}{|c|}{ Model 2} & \multirow{2}{*}{ dX, m } & \multirow{2}{*}{ dY, m } & \multirow{2}{*}{$\mathbf{d H}, \mathrm{m}$} \\
\hline & $\mathbf{X}, \mathbf{m}$ & $\mathbf{Y}, \mathbf{m}$ & $\mathrm{H}, \mathrm{m}$ & $\mathbf{X}, \mathbf{m}$ & $\mathbf{Y}, \mathbf{m}$ & H, m & & & \\
\hline 3 & 998.404 & 008.655 & 100.205 & 998.433 & 008.692 & 100.103 & -0.029 & -0.037 & 0.102 \\
\hline 6 & 02.208 & 1012.971 & 100.546 & 1002.207 & 101 & 00.603 & 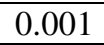 & -0.013 & -0.057 \\
\hline 7 & & & & 1010.944 & & & & 0.027 & 0.062 \\
\hline 8 & 05.892 & & & 1005.923 & & & -0.031 & 0.011 & 0.117 \\
\hline 9 & 00.873 & & 100.820 & 1000.846 & & & .027 & 0.013 & 0.097 \\
\hline 10 & 995.374 & 101 & 100.779 & & & 100.789 & & -0.017 & -0.010 \\
\hline 11 & 990.671 & 1018.398 & 100.613 & 990.679 & 1018.427 & 100.579 & -0.008 & -0.029 & 0.034 \\
\hline 12 & 991.219 & & 101.375 & & & & & -0.032 & -0.074 \\
\hline 13 & 9 & & & & & & & & 019 \\
\hline 14 & 6 & & 7 & 100 & & & & & 024 \\
\hline 15 & 74 & 102 & 101 & 100 & & ד ד & 3 & 0.008 & 0.017 \\
\hline 16 & 101 & 102 & 101 & 101 & & & -0.018 & 0.022 & -0.049 \\
\hline 17 & 014.786 & 1027.010 & 102.197 & 1014 & & 102 & -0.023 & 0.006 & -0.110 \\
\hline 18 & 1010.709 & & 102.607 & 101 & & & & 0.026 & -0.039 \\
\hline 19 & & & & & & & & & -0.016 \\
\hline 20 & & & & & & & & & -0.080 \\
\hline 21 & 9 & & & & & 10 & 3 & .028 & 0.045 \\
\hline 22 & 9 & & & & & 12 & .009 & 015 & 0.057 \\
\hline 23 & 998.130 & 103 & 104.001 & 998.161 & 103 & 104.098 & -0.031 & 0.001 & -0.097 \\
\hline 24 & 1005.783 & 1036.192 & 103.927 & 1005.769 & 1036.191 & 103.861 & 0.014 & 0.001 & 0.066 \\
\hline 25 & & & & 1012.732 & & & & 0.022 & 0.067 \\
\hline 26 & & & & & & & & & 0.119 \\
\hline 27 & & & & & & & 9 & 30 & 0.080 \\
\hline 28 & 00 & 1( & 10 & 101 & & 105 & 5 & 022 & 0.088 \\
\hline 29 & 1007.566 & 104 & 105.290 & 1007.584 & 1043.697 & 105.381 & -0.018 & -0.026 & -0.091 \\
\hline 30 & 998.942 & 1045.279 & 105.715 & 998.977 & 1045.289 & 105.776 & -0.035 & -0.010 & -0.061 \\
\hline 31 & 991.596 & 1046.482 & 105.546 & & 1046.507 & 105.629 & 0.005 & -0.025 & -0.083 \\
\hline 32 & & & & & & 107.197 & 36 & 0.016 & -0.045 \\
\hline 33 & & & & & & & & & 0.041 \\
\hline 34 & & & & & & & & -0.019 & 0.013 \\
\hline 35 & & & 107. & & & 107.327 & 0.024 & -0.024 & -0.029 \\
\hline 36 & 1017.724 & 1051.776 & 107.050 & 1017.728 & 1051.772 & 107.003 & -0.004 & 0.004 & 0.047 \\
\hline
\end{tabular}

Calculation of the differences of the coordinates of the model points (method 1) 
In the second case the accuracy was estimated based on the true errors of the coordinates of the points of the first model and the model generated using the data of the total station surveying [15-17]. The coordinates of the points received by the total station were taken as true values. The calculation of the differences of coordinates is presented in Table 4. The calculation of the RMSE of the plane coordinates and the heights was made according to the formulas 5; 6. The RMSE of the plane coordinates was $0.036 \mathrm{~m}$, and the RMSE of the heights was $0.071 \mathrm{~m}$

$$
\begin{gathered}
m_{X: Y}=\sqrt{\frac{\left[X^{2}\right]+\left[Y^{2}\right]}{n}} \\
m_{H}=\sqrt{\frac{\left[H^{2}\right]}{n}}
\end{gathered}
$$

where $m_{x: y}-$ RMSE of the plane coordinates, $\mathrm{m}$;

$\Delta X, \Delta Y$ - differences of the plane coordinates, $\mathrm{m}$;

$m_{H}-$ RMSE of the heights, $\mathrm{m}$;

$\Delta H$ - differences of the heights, $\mathrm{m}$;

$n$ - number of the points.

Table 4

\begin{tabular}{|c|c|c|c|c|c|c|c|c|c|}
\hline \multirow{2}{*}{ Point } & \multicolumn{3}{|c|}{ Model 3} & \multicolumn{3}{|c|}{ Model 1} & \multirow{2}{*}{$\Delta \mathbf{X}, \mathbf{m}$} & \multirow{2}{*}{$\Delta \mathbf{Y}, \mathbf{m}$} & \multirow{2}{*}{$\Delta \mathbf{H}, \mathbf{m}$} \\
\hline & $\mathbf{X}, \mathbf{m}$ & $\mathbf{Y}, \mathbf{m}$ & H, m & $\mathbf{X}, \mathbf{m}$ & $\mathbf{Y}, \mathbf{m}$ & $\mathbf{H}, \mathbf{m}$ & & & \\
\hline 3 & 998.395 & 008.610 & 100.274 & 998.404 & 1008.655 & 100.205 & .009 & 0.045 & -0.069 \\
\hline 6 & 002.202 & 13.011 & 00.479 & 002.208 & 12.971 & 100.546 & & & .067 \\
\hline 7 & & & & & & & & & \\
\hline 8 & & & & & & & & & 094 \\
\hline 9 & & & & & & & & & 076 \\
\hline 10 & 995.401 & 101 & & & 752 & & 27 & .021 & 0.091 \\
\hline 11 & 990.640 & & & & & & & & .071 \\
\hline 12 & 991.187 & & & & & & & & .073 \\
\hline 13 & & & & & & & & & \\
\hline 14 & & & & & & & & & 057 \\
\hline 15 & & & & & & & 4 & & 087 \\
\hline 16 & & & & & & & 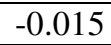 & .004 & .087 \\
\hline 17 & & & & 10 & & & 33 & .010 & 0.066 \\
\hline 18 & 0 & & & & & & & & 0.062 \\
\hline 19 & & & & & & & & & .042 \\
\hline 20 & & & & & & & & & .077 \\
\hline 21 & & & & & & & & & .081 \\
\hline 22 & & & & & & & & & 068 \\
\hline 23 & & & & & & & & 6 & .086 \\
\hline 24 & & & & & & & & 0.0 & 0.076 \\
\hline 25 & & & & & & & & & 0.100 \\
\hline 26 & & & & & & & & & 068 \\
\hline 27 & & & & & & & & & \\
\hline 28 & & & & & & & & & .093 \\
\hline 29 & & & & 10 & & & 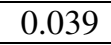 & 0.005 & .061 \\
\hline 30 & & & & & 279 & 715 & 34 & 040 & 0.033 \\
\hline 31 & 9 & & & & 482 & 546 & .033 & 002 & .055 \\
\hline 32 & 9 & & & & 838 & 152 & .049 & 0.045 & 0.059 \\
\hline 33 & & & & & & & & & 041 \\
\hline 34 & & & & & & & & & .081 \\
\hline 35 & & & & & & & & & .058 \\
\hline 36 & 1017.694 & 1051.790 & 107.093 & 1017.724 & 1051.776 & 107.050 & 0.030 & -0.014 & -0.04 \\
\hline
\end{tabular}

Calculation of the differences of the coordinates of the model points $(\operatorname{method} 2)$ 


\section{Results and discussion}

According to the results of the assessment of accuracy, we can say that the accuracy of the coordinates of the points of the models generated using the photos from the UAV is quite high and is comparable with the results of the ground-based measurements. It is quite possible to use such DTM for solving land management tasks.

At the same time, the density of points of such models is much higher than the density of points of the models generated using ground surveys, and this gives a more detailed view of the terrain in a particular area.

\section{Conclusions}

1. It is possible to use UAVs, equipped with semi-professional digital cameras, to generate a highdensity DTM of a requiredaccuracy.The density of points of the DTM, generated using the photos from the UAVs, is much higherthan the density of points of the DTM, generated as a result of ground surveys.

2. It has been experimentally proven that images obtained during aerial surveyingwith UAVs with reasonable parameters (flight height, image base, overlap) allow DTM generation of arequired accuracy. So, according to the images obtained by a camera with a principal distance of $3.61 \mathrm{~mm}$ at a scale of 1:7200 the DTM was generated with RMSE of heights of $0.07 \mathrm{~m}$ for a required RMSE of $0.10 \mathrm{~m}$.

3. The accuracy of the DTM, generated by the photogrammetric method with a different set of reference points, was estimated from the difference in double measurements. RMSE, characterizing the accuracy of the heights of the DTM points, was $0.05 \mathrm{~m}$.

\section{References}

[1] Ruzgienė B., Berteška T., Gečyte S. etc. The surface modelling based on UAV Photogrammetry and qualitative estimation. Measurement, vol. 73, 2015, pp. 619-627.

[2] Uysal M., Toprak A., Polat N. DEM generation with UAV Photogrammetry and accuracy analysis in Sahitler hill, Measurement, vol. 73, 2015, pp. 539-543.

[3] Tonkin T., Midgley N., Graham D., Labadz J. The potential of small unmanned aircraft systems and structure-from-motion for topographic surveys: A test of emerging integrated approaches at Cwm Idwal, North Wales. Geomorphology, vol. 226, 2014, pp. 35-43.

[4] Yang C., Tsai M., Kang S., Hung C. UAV path planning method for digital terrain model reconstruction - A debris fan example. Automation in Construction, vol. 93, 2018, pp. 214-230.

[5] Ajayi O., Palmer M.,Salubi A. Modelling farmland topography for suitable site selection of dam construction using unmanned aerial vehicle (UAV) photogrammetry. Remote Sensing Applications: Society and Environment, vol. 11, 2018, pp. 220-230.

[6] Pádua L., Adão T.,Hruška J. Very high resolution aerial data to support multi-temporal precision agriculture information management. Procedia Computer Science, vol. 121, 2017, pp. 407-414.

[7] Saad A.,Tahar K. Identification of rut and pothole by using multirotor unmanned aerial vehicle (UAV). Measurement, vol. 137, 2019, pp. 647-654.

[8] Gulam V.,Gajski D.,Podolszki L. Photogrammetric measurement methods of the gully rock wall retreat in Istrian badlands. CATENA, vol. 160,2018, pp. 298-309.

[9] Rusnák M.,Sládek J.,Kidová A.,Lehotský M. Template for high-resolution river landscape mapping using UAV technology. Measurement, vol: 115, 2018, pp: 139-151.

[10] Chen B., Yang Y., Wen H. High-resolution monitoring of beach topography and its change using unmanned aerial vehicle imagery. Ocean \& Coastal Management, vol. 160, 2018, pp. 103-116.

[11]Colomina I., Molina P. Unmanned aerial systems for photogrammetry and remote sensing: A review. ISPRS Journal of Photogrammetry and Remote Sensing, vol. 92, 2014, pp. 79-97.

[12] Pajares G. Overview and Current Status of Remote Sensing Applications Based on Unmanned Aerial Vehicles (UAVs). Photogrammetric Engineering \& Remote Sensing, vol. 81 (4), 2015, pp. 281-329.

[13] Nikolakopoulos K.,Soura K.,Koukouvelas I.,Argyropoulos N. UAV vs classical aerial photogrammetry for archaeological studies. Journal of Archaeological Science: Reports, vol. 14, 2017, pp. 758-773 
[14] James M., Robson S.,d'Oleire-Oltmanns S.,Niethammer U. Optimising UAV topographic surveys processed with structure-from-motion: Ground control quality, quantity and bundle adjustment. Geomorphology, vol. 280,2017, pp. 51-66.

[15] Martínez-Carricondo P., Agüera-Vega F., Carvajal-Ramírez F. etc. Assessment of UAVphotogrammetric mapping accuracy based on variation of ground control points. International Journal of Applied Earth Observation and Geoinformation, vol. 72, 2018, pp. 1-10.

[16] Babinec A., Apeltauer J. On accuracy of position estimation from aerial imagery captured by lowflying UAVs. International Journal of Transportation Science and Technology, vol. 5 (3), 2016, pp. 152-166.

[17] Kršák B., Blišt’an P., Pauliková A. etc. Use of low-cost UAV photogrammetry to analyze the accuracy of a digital elevation model in a case study. Measurement, vol. 91, 2016, pp. 276-287. 